\title{
Dossiê
}

\section{Circulação e conformações de saberes no Império português, séculos XVI-XIX}

\author{
HELOISA MEIRELES GESTEIRA \\ Museu de Astronomia e Ciências Afins | MCTI PPGHIS-UNIRIO
}

THOMÁS A. S. HADDAD

Escola de Artes, Ciências e Humanidades da Universidade de São Paulo | EACH/USP

Porque os Portugueses, que navegam muita parte do mundo, onde vão nam procurão de saber senam como farão milhor suas mercadorias [...] Não são curiosos de saber as cousas que ha na terra, e, se as sabem, nam dizem a quem lhas traz que the amostre o arvore, e, se o vêem, nam o compárão a outro arvore nosso, nem proguntao se dá frol ou fruto, e que tal he.

Esta sentença foi estampada em 1563, em Goa, por ninguém menos que Garcia de Orta em seus Colóquios dos simples e drogas he cousas mediçinais da Índia. 0 conde de Ficalho, editor de Orta para a Academia das Ciências de Lisboa em fins do século XIX, houve por bem reforçar o veredito, anotando no pé da página um comentário seco sobre essa passagem: "Reflexão perfeitamente sentida, e que ainda hoje tem cabimento". Esse desinteresse, essa falta de curiosidade a respeito das "cousas que há na terra" são parte fundamental da legenda negra que envolveu -e ainda envolve - muito do que já se disse sobre os projetos coloniais dos impérios ibéricos. Os próprios portugueses não fizeram pouca coisa para disseminá-la, e a narrativa da decadência, da superstição religiosa e da irracionalidade se estabeleceu com toda força na época do reformismo ilustrado, acompanhando todo o século XIX e as primeiras décadas do XX.

No Estado Novo salazarista, esboçou-se uma reação. A singularidade da experiência colonial portuguesa foi louvada em múltiplos cantos; sua capacidade de adaptação, seu estar no mundo eminentemente prático e tolerante, sua missão civilizacional foram glorificados. De maneira paradoxal, no entanto, a produção de saberes sobre o Império permaneceu vista como uma excepcionalidade - excepcionalidade de gênios, bem entendido, homens como o próprio Orta, Duarte Pacheco Pereira, D. João de Castro ou Pedro Nunes, em torno dos quais se construiu uma tradição triunfalista e patriótica. Curiosamente, as primeiras reações a essa historiografia, que se começam a esboçar nos estertores do Império Colonial cinco décadas atrás, mantiveram a condição de exceção desses homens do século XVI, e acabaram 
por reforçar, de certa maneira, a parcela da legenda negra que afirmava que, por centenas de anos, os portugueses sustentaram um Império sobre o qual não se interessaram intelectualmente. Sentença ainda mais forte quando se comparava à experiência do colonialismo neerlandês, francês e inglês do período.

Esse movimento, afastado dos imperativos de certo lusotropicalismo e de ideologias congêneres, teve a salutar consequência de nos chamar a atenção para o papel fundacional da violência e do racismo na conformação da empreitada imperial lusitana por mais de quatrocentos anos, até bem entrado o século XX. Em lugar das narrativas da tolerância e da civilização, temos hoje a consciência aguda do lugar central ocupado pela força bruta em todo esse processo. Terá então Orta sido vindicado, estabelecendo-se que os portugueses só se interessaram por comerciar (inclusive com seres humanos como mercadorias)? Os últimos anos têm indicado que não.

A consciência da lógica econômica e da prática brutal tem convivido com uma percepção cada vez mais consolidada de que instrumentos intelectuais de controle dos espaços, de suas gentes e de sua natureza também foram largamente empregados pelos portugueses, em seu próprio território europeu e em todas as conquistas ultramarinas. Ao contrário do que denunciaram Orta e sucessivas gerações de portugueses, eles foram sim muito curiosos das terras que encontraram, e não só em casos excepcionais. Assim, o estudo da formação de corpos de saberes necessários à constituição da ordem imperial, envolvendo práticas e conhecimentos administrativos, tecnológicos, demográficos e de inventário da natureza, ocupa hoje lugar central no programa de investigação de muitos historiadores da ciência, mas não apenas.

De fato, até meados do século XVII, Portugal tinha sob seu controle a maior e mais extensa rede mundial de portos marítimos e entrepostos comerciais, indo da América do Sul ao Japão, passando pelas duas costas da África, pela Índia e por diversos pontos da Ásia Meridional. Entre os mecanismos de controle dos domínios ultramarinos, a produção de saberes sobre os lugares e sobre os povos teve um lugar de destaque desde os primórdios da expansão marítima e esteve presente no colonialismo até a primeira metade do século XX. Mesmo após a entrada em cena de potências imperiais concorrentes, cosmógrafos, matemáticos, engenheiros, naturalistas, médicos e geógrafos a serviço de Portugal estavam espalhados pelo mundo todo, ao lado de outros agentes sociais como mercadores, missionários, marinheiros, administradores e colonos. Esses atores estiveram envolvidos, desde o século XV, nos mais variados processos de coleta, organização e troca de informações, na forma de saberes sobre o mundo natural e 0 território, organização social, práticas religiosas, matéria médica e muito mais. Os diversos produtos deste imenso inventário, bem como seus meios de produção, circularam, de forma manuscrita ou impressa, em livros, cartas, memórias, roteiros, mapas e imagens, ou ainda se materializaram em instrumentos e outros artefatos.

A circulação de informações e saberes sobre o Império, dentro dele e através das suas fronteiras, interessa-nos especialmente aqui. Primeiro, cabe investigar as diferentes modalidades em que os próprios saberes se organizaram, sem projetar no passado categorias disciplinares modernas. Como, por exemplo, não desconsiderar o impacto da circulação de informações em forma manuscrita e não impressa durante a Época Moderna. Essas modalidades devem ser estabelecidas tendo-se em vista seu lugar na estrutura das lógicas imperiais que se sucederam e às vezes coexistiram, e devem ser pensadas em situações históricas concretas. A dimensão complementar é o estudo do conteúdo desses corpos de conhecimento, os usos que lhes foram dados e seu estatuto comparativamente a saberes da mesma natureza produzidos por outros atores. É então que se impõe a análise das formas de circulação: público, suportes materiais, obstáculos e alcance. Os hitoriadores das ciências têm reconhecido cada vez mais que a circulação é um processo ativo em que o conhecimento é muitas vezes transformado, ressignificado e "universalizado", a partir de sua ancoragem sempre local na incepção. As ciências modernas, longe de serem uma dádiva de algumas pessoas e instituições da Europa Ocidental ao mundo, são fruto de processos circulatórios em diversas escalas - e a do Império Português é forçosamente uma delas.

Os artigos aqui reunidos pretendem, a partir de casos específicos, analisar saberes, ciências e práticas culturais que deram lastro aos processos imperiais de controle e transmissão a longa distância, tais como evidenciados nas formas de intercâmbio, nos objetos e nos mecanismos de visibilidade e comunicação empregados na circulação do 
conhecimento sobre o Império Português, ao longo de alguns séculos de sua existência. Outro eixo de reflexão é a própria relação entre os saberes e o modelo imperial português, com atenção especial aos processos de coleta, formalização e disseminação do conhecimento adquirido nas possessões ultramarinas e no Reino. Investigam ainda quais os aspectos relevantes da interação entre "eruditos" e comunidades ou informantes locais, quais eram os mecanismos de difusão e legitimação do conhecimento construído em situações de contato cultural e quais os efeitos da competição e colaboração intra- e inter-imperiais na conformação dos saberes em circulação.

Abrimos o dossiê com o artigo de Lorelai Kury, A ciência útil em 0 patriota (Rio de Janeiro, 1813-1814). 0 texto nos convida a refletir sobre as caracterísitcas do llumismo luso-brasileiro, sobretudo no que diz respeito ao papel da imprensa na difusão não apenas das ideias, mas também como meio de propagar as novas formas de aproveitamento dos recursos naturais e as inovações técnicas que deveriam auxiliar o trabalho. Visto como um movimento reformador, 0 Iluminismo, conforme apresentado por Lorelai Kury, "centrou suas propostas na racionalização do uso da terra, na busca de produtos agrícolas e de origem animal alternativos, na descrição e quantificação das populações e suas atividades, na listagem, classificação e utilização dos chamados três reinos da natureza.".

Tema caro à historiografia das ciências e da tecnologia no Brasil e em Portugal, as Viagens Filosóficas, ocorridas durante a llustração, são aqui tratadas por Ermelinda Moutinho Pataca do ponto de vista de sua estruturação, teórica e prática, explorando as etapas de preparação, execução e sistematização dos dados coletados nos vários pontos do Império, processo fomentado pelo Estado e organizado a partir de instituições situadas em Lisboa, em especial o Real Museu e Jardim Botânico do Real Palácio da Ajuda. Em seu artigo, “Coletar, preparar, remeter, transportar - práticas de História Natural nas viagens filosóficas portuguesas (1777-1808)", a autora nos mostrou como, embora os resultados não tenham sido publicados, o empreendimento não pode ser considerado um "fracasso", uma vez que as "práticas", "técnicas" e "representações" resultantes de todo o processo, inclusive a formação de uma rede de informações que surgiu durante a preparação e realização das viagens científicas no Império português.

0 artigo seguinte, Censura e mercê: os pedidos de leitura e posse de livros proibidos em Portugal no século XVIII, traz uma contribuição que pode nos levar a novas interpretações sobre a llustração luso-brasileira, momento bastante estudado por historiadores da Ciência e da Tecnologia entre nós. Ao analisar os pedidos de licença enviados por homens públicos, professores e clérigos aos órgãos censores de Portugal, Cláudio DeNipoti e Thais Nivea de Lima e Fonseca nos mostram como esta elite letrada tinha acesso à posse de livros que tratavam de temas "perigosos" escritos pelos filósofos ilustrados de várias partes da Europa que constavam nas listas das leituras proibidas, demonstando, assim, como havia circulação de saberes e ideias, ainda que com acesso restrito, obedecendo à lógica do privilégio da sociedade do Antigo Regime. Entre os livros, havia obras e temas importantes da cultura científica da llustração.

Fechamos este dossiê com o texto de Thomás Haddad que nos leva ao período anterior ao lluminismo e ao Império português observado pelo holandês Jan Huygen van Linschoten (c. 1563-1611), em seu livro Itinerário, publicado em 1596. 0 livro, além de conter roteiros de viagem, ficou famoso por tratar dos portugueses no Oriente. Além de uma apresentação sumária dos conteúdos tradicionais do "conhecimento colonial" que se constitui junto com a expansão europeia, Thomás Haddad explora, sobretudo, os aspectos de uma "etnografia implícita", refletindo sobre o tema da miscigenação, tão caro à compreensão do império português e visto com olhos críticos pelo observador batavo.

Por tudo isto, vemos o conjunto de artigos aqui publicados não como ponto de chegada, mas, sobretudo, como estímulo a novas pesquisas e questionamentos que se atenham ao papel da produção de saberes articulados ao processo de expansão portuguesa desde os seus primórdios. Acreditamos que historiadores da ciência podem contribuir ainda muito para o estabelecimento de novas investigações sobre esta temática. 